\title{
Desempenho, composição da cama, das tíbias, do fígado e das excretas de frangos de corte alimentados com rações contendo fitase e baixos níveis de fósforo ${ }^{1}$
}

\author{
Antonio Carlos de Laurentiz ${ }^{2}$, Otto Mack Junqueira ${ }^{3}$, Rosemeire da Silva Filardi², Karina \\ Ferreira Duarte ${ }^{4}$, Vinícius Assuena ${ }^{4}$, Sarah Sgavioli ${ }^{4}$
}

1 Projeto financiado pela FAPESP. Proc. 2001/12967-6.

2 Departamento de Biologia e Zootecnia da Universidade Estadual Paulista Júlio de Mesquita Filho, Faculdade de Engenharia de Ilha SolteiraUNESP.

${ }^{3}$ Departamento de Zootecnia da Universidade Estadual Paulista Júlio de Mesquita Filho, Faculdade de Ciências Agrárias e Veterinárias de Jaboticabal - UNESP.

${ }^{4}$ Programa de Pós-graduação da Universidade Estadual Paulista Júlio de Mesquita Filho, Faculdade de Ciências Agrárias e Veterinárias de Jaboticabal - UNESP.

RESUMO - Um experimento foi realizado para avaliar o desempenho e a composição da cama, das tíbias, do fígado e das excretas de frangos de corte em diversas fases utilizando-se diferentes níveis de fósforo disponível (Pd) e da enzima fitase. Foram utilizados 1.200 pintos machos de 1 dia de idade, da marca comercial Cobb, distribuídos em delineamento inteiramente casualizado, em esquema fatorial $4 \times 3$, composto de quatro níveis de fósforo disponível e três níveis de fitase: 0 , 500 e $1.000 \mathrm{ftu} / \mathrm{kg}$ de ração, cada um com quatro repetições de 25 aves. Os níveis de fósforo disponível foram obtidos considerando quatro disponibilidades do fósforo total $(\mathrm{Pt})$ do milho e do farelo de soja (34, 56, 78 e 100\% de disponibilidade). Foram avaliados os índices de desempenho no final de cada fase de criação e aos 42 dias de idade. Os parâmetros de desempenho foram afetados pela redução dos níveis de fósforo disponível das rações e a redução desse elemento para níveis inferiores a $19 \%$ piorou o desempenho das aves, enquanto a utilização de fitase no nível de Pd reduzido em $39 \%$ melhorou o desempenho. Nas fases de criação, a redução do teor de fósforo disponível com a utilização da enzima fitase influencia o desempenho e as características da cama e dos ossos.

Palavras-chave: consumo de ração, ganho de peso, índice de eficiência de produção, viabilidade criatória

\section{Performance, litter composition, tibia, liver and excreta of broilers fed diets containing reduced levels of phosphorus and phytase enzyme}

\begin{abstract}
An experiment was conducted to evaluate the performance and composition of litter, tibia, liver and excreta of broiler chicks at different phases using different levels of available phosphorous (Pd) and the enzyme phytase. One thousand and two hundred one-day-Cobb-male chicks were used, distributed in a randomized complete design, using a $4 \times 3$ factorial arrangement, consisting of four available phosphorus levels and three phytase levels - 0, 500 and 1,000 FTU phytase $/ \mathrm{kg}$ of diet with four replications of 25 birds each. The levels of available phosphorus were obtained considering four different availabilities of total phosphorus $(\mathrm{Pt})$, corn and soybean meal $(34,56,78$ and $100 \%$ availability). The performance indices were evaluated at the end of each breeding phase and at the age of 42 days. The performance parameters were affected by the reduction in available phosphorus levels in the diets and the reduction of this element to levels below $19 \%$ affected negatively the performance and the use of phytase in available phosphorus level reduced in $39 \%$ improved the performance of the broilers. In the growing phases, reduction in the available phosphorus content using the phytase enzyme influenced the performance and the litter and bone characteristics.
\end{abstract}

Key Words: breeding viability, feed intake, productive efficiency index, viability, weight gain 


\section{Introdução}

Entre os minerais exigidos pelas aves, o fósforo e o cálcio são os mais importantes, por serem necessários não apenas para a ótima taxa de crescimento, mas também para a mineralização óssea. No entanto, o custo desse mineral é muito alto, pois é inferior apenas ao da energia e da proteína no total de formulação de rações para aves e suínos (Borges, 1997). A alimentação das aves se baseia principalmente na mistura de ingredientes vegetais, todavia, cerca de dois terços do fósforo contido nos grãos de cereais e sementes oleaginosas encontram-se na forma de fitato, capaz de se ligar a outros nutrientes, tornando-os indisponíveis a aves e suínos (Denbow et al., 1995).

Visando à redução dos custos de produção, o enfoque nas pesquisas atuais tem sido a busca pela melhora na eficiência de utilização de alimentos, associada ao menor impacto no ambiente pela concentração da produção animal, com base no conhecimento da disponibilidade dos nutrientes provenientes dos ingredientes da formulação de ração dentro das exigências nutricionais. Assim, é fundamental a realização de pesquisas para se conhecer o efeito da adição de enzimas exógenas microbianas sobre a disponibilidade de nutrientes.

A enzima fitase tem sido produzida industrialmente a partir de microrganismos por meio de técnicas de recombinação de DNA e seu potencial consiste em melhorar a disponibilidade de fósforo nos ingredientes de origem vegetal presentes na forma de fitato. Assim, a adição dessa enzima permite que as aves absorvam o fósforo de maneira eficiente, reduzindo a necessidade de suplementação de fósforo inorgânico, melhorando o ganho de peso, a conversão alimentar, o consumo de ração e a mineralização óssea, e reduzindo a mortalidade (Qian et al., 1996).

Na determinação das exigências nutricionais de fósforo disponível para aves, é importante considerar que as características dos ossos são mais sensíveis que as de desempenho (Gomes et al., 1993). Dessa forma, o nível de fósforo disponível nas dietas deve ser suficiente para garantir, além do ótimo desempenho, boa formação e resistência óssea.

Junqueira et al. (1993) compararam a farinha de carne e ossos com o fosfato bicálcico como fonte de fósforo na ração para frangos de corte utilizando níveis de $0,7 \%$ de fósforo total (Pt) para a fase de 1 a 28 dias e níveis de 0,7 ; 0,6 ; e $0,5 \%$ de fósforo total para o período de 29 a 40 dias. Os resultados indicaram que a farinha de carne e ossos, ou o fosfato bicálcico, não afetaram o desenvolvimento das aves de 1 a 28 dias quando se utilizou o nível de $0,7 \%$ de Pt.
Este estudo foi realizado com o objetivo de estudar os níveis de suplementação da enzima fitase e os efeitos dos níveis de fósforo em rações sobre o desempenho e a composição da cama, das tíbias, do fígado e das excretas de frangos de corte.

\section{Material e Métodos}

Foram alojados 1.200 pintos machos de 1 dia de idade, com peso inicial médio de $42,5 \mathrm{~g}$, em galpão convencional de alvenaria com cama de maravalha, na quantidade de $1,2 \mathrm{~kg}$ de matéria seca por ave alojada por boxe (Tabela 1). O delineamento experimental foi inteiramente casualizado, em esquema fatorial $4 \times 3$, composto de 4 níveis de fósforo disponível e 3 níveis de enzima fitase, totalizando 12 tratamentos e 4 repetições de 25 aves em cada parcela.

Os níveis de fósforo disponível (Pd) para a fase inicial ( 1 a 21 dias) foram 0,$45 ; 0,37 ; 0,29$ e $0,21 \%$; para a fase de crescimento ( 22 a 35 dias) 0,$41 ; 0,33 ; 0,25$ e $0,17 \%$ e, para a fase final (36 a 42 dias de idade), 0,37; 0,29; 0,21 e 0,13\%. Consideraram-se quatro disponibilidades do fósforo total (Pt) para o milho e o farelo de soja: $34 \%$ da disponibilidade real (Rostagno et al., 2000) e 56, 78 e 100\% de disponibilidade. Com essas disponibilidades de fósforo total, a redução dos níveis de fósforo disponível das rações dentro de cada fase de criação foi de $18,36,54 \% ; 19,38,58 \%$ e 21, 43 , $64 \%$, respectivamente, para as fases inicial, de crescimento e final (Tabela 2), obtendo-se assim reduções médias de 19, 39 e $58 \%$ para a fase total de criação ( 1 a 42 dias de idade). Os níveis de fitase utilizados foram 0,100 e $200 \mathrm{~g} /$ tonelada, garantindo 0, 500 e $1000 \mathrm{ftu} / \mathrm{kg}$ de ração, conforme recomendação do fabricante (Natuphos $5.000^{\circledR}$ - BASF).

As rações experimentais foram isonutritivas, à base de milho e farelo de soja, e formuladas conforme recomendações nutricionais, considerando a composição dos ingredientes descrita por Rostagno et al. (2000), com variações apenas nos níveis de fósforo disponível (\%), de acordo com a disponibilidade de fósforo total do milho e do farelo de soja (Tabela 3).

Tabela 1 - Composição das amostras da maravalha utilizada como cama

\begin{tabular}{lcccc}
\hline Maravalha & $\begin{array}{c}\text { Fósforo } \\
\text { total }(\%)\end{array}$ & $\begin{array}{c}\text { Manganês } \\
(\mathrm{ppm})\end{array}$ & $\begin{array}{c}\text { Cobre } \\
(\mathrm{ppm})\end{array}$ & $\begin{array}{c}\text { Zinco } \\
(\mathrm{ppm})\end{array}$ \\
\hline Amostra 1 & 0,12 & 48 & 10 & 29 \\
Amostra 2 & 0,13 & 37 & 9 & 32 \\
Amostra 3 & 0,04 & 50 & 13 & 31 \\
Amostra 4 & 0,09 & 43 & 15 & 25 \\
\hline
\end{tabular}

Valores determinados no Laboratório da Serrana Nutrição Animal S/A. 
Tabela 2 - Composição em fósforo dos ingredientes utilizados nas rações experimentais

\begin{tabular}{lcc}
\hline Ingrediente & Fósforo total $(\%)$ & Fósforo disponível $(\%)^{1}$ \\
\hline Milho & 0,23 & 0,08 \\
Farelo de soja & 0,52 & 0,17 \\
Fosfato bicálcico & 18,2 & 18,2 \\
Calcário calcítico & - & -
\end{tabular}

Valores determinados no Laboratório da Serrana Nutrição Animal S/A.

${ }^{1}$ Considerou-se disponibilidade de $33 \%$ do fósforo do milho e do farelo de soja, conforme descrito por Rostagno et al. (2000).

Dentro de cada fase de criação, realizou-se o controle de peso, do consumo de ração e da conversão alimentar. Ao final do período experimental (42 dias de idade), avaliaram-se o índice de eficiência de produtividade (IEP $=$ [ganho de peso médio diário $(\mathrm{g}) \times$ viabilidade criatória $(\%)] /($ conversão alimentar $\times 10)$ ), a produção de matéria seca de cama, o coeficiente de resíduo e os teores de proteína bruta, fósforo, zinco, manganês e cobre das camas de frango. Foram sacrificadas duas aves por parcela para quantificar os teores de cinzas, utilizando-se as tíbias, e de fósforo, zinco, manganês e cobre, utilizando-se as tíbias e o fígado.
As análises de fósforo e dos microminerais foram realizadas segundo metodologia da AOAC (1990). A solução mineral para determinação de fósforo foi obtida das cinzas por via seca e quantificada pelo método de fotometria. Para determinação do zinco, manganês e cobre, obteve- se a solução mineral por via úmida utilizando-se o método de espectrofotometria de absorção atômica.

A quantidade inicial de maravalha utilizada como substrato para cama de frango foi de $1,2 \mathrm{~kg}$ de matéria seca por ave em cada parcela, de forma que, em todas as unidades tiveram a mesma quantidade inicial do material utilizado como cama. O coeficiente de resíduo foi calculado dividindo-se a quantidade total de cama produzida ( $\mathrm{kg}$ de $\mathrm{MS} /$ parcela) pela quantidade total de peso vivo produzido (kg da parcela) aos 42 dias de idade.

Aos 35 dias de idade, duas aves por parcela experimental foram transferidas para gaiolas de metabolismo, adaptadas com bandejas para coleta de excretas durante sete dias. Após a coleta, as excretas foram congeladas e posteriormente processadas de acordo com Silva (1990), para a obtenção dos seus teores de fósforo, manganês, cobre e zinco.

Tabela 3 - Composição das rações experimentais fornecidas em cada fase

\begin{tabular}{|c|c|c|c|c|c|c|c|c|c|c|c|c|}
\hline & \multicolumn{12}{|c|}{ Nível de disponibilidade do fósforo total $(\%)^{2}$} \\
\hline & $0,45(\mathrm{~A})$ & $0,37(\mathrm{~B})$ & $0,29(\mathrm{C})$ & $0,21(\mathrm{D})$ & $0,41(\mathrm{~A})$ & $0,33(\mathrm{~B})$ & $0,25(\mathrm{C})$ & $0,17(\mathrm{D})$ & $0,37(\mathrm{~A})$ & $0,29(\mathrm{~B})$ & $0,21(\mathrm{C})$ & $0,13(\mathrm{D})$ \\
\hline \multicolumn{13}{|l|}{ Composicão em ingredientes (\%) } \\
\hline Milho & 56,92 & 56,92 & 56,92 & 56,92 & 59,87 & 59,87 & 59,87 & 59,87 & 67,72 & 67,72 & 67,72 & 67,72 \\
\hline Farelo de soja & 37,30 & 37,30 & 37,30 & 37,30 & 31,80 & 31,80 & 31,80 & 31,80 & 26,40 & 26,40 & 26,40 & 26,40 \\
\hline Suplemento mineral vitamínico ${ }^{3}$ & 0,60 & 0,60 & 0,60 & 0,60 & 0,60 & 0,60 & 0,60 & 0,60 & 0,30 & 0,30 & 0,30 & 0,30 \\
\hline Fosfato bicálcico & 1,76 & 1,33 & 0,90 & 0,46 & 1,59 & 1,18 & 0,77 & 0,36 & 1,40 & 1,01 & 0,58 & 0,15 \\
\hline Calcário calcítico & 1,01 & 1,29 & 1,57 & 1,85 & 1,03 & 1,29 & 1,56 & 1,82 & 1,04 & 1,29 & 1,56 & 1,84 \\
\hline DL-metionina (99\%) & 0,15 & 0,15 & 0,15 & 0,15 & 0,13 & 0,13 & 0,13 & 0,13 & 0,09 & 0,09 & 0,09 & 0,09 \\
\hline Lisina $(78 \%)$ & 0,03 & 0,03 & 0,03 & 0,03 & 0,06 & 0,06 & 0,06 & 0,06 & 0,05 & 0,05 & 0,05 & 0,05 \\
\hline Porção variável ${ }^{1}$ & 0,02 & 0,17 & 0,32 & 0,48 & 0,02 & 0,17 & 0,31 & 0,46 & 0,02 & 0,16 & 0,32 & 0,47 \\
\hline Cálcio $(\%)$ & 0,96 & 0,96 & 0,96 & 0,96 & 0,90 & 0,90 & 0,90 & 0,90 & 0,80 & 0,80 & 0,80 & 0,80 \\
\hline Fósforo disponível (\%) & 0,45 & 0,37 & 0,29 & 0,21 & 0,41 & 0,33 & 0,25 & 0,17 & 0,37 & 0,29 & 0,21 & 0,13 \\
\hline Fósforo total $(\%)$ & 0,70 & 0,61 & 0,53 & 0,45 & 0,63 & 0,55 & 0,48 & 0,40 & 0,58 & 0,51 & 0,43 & 0,35 \\
\hline Lisina total $(\%)$ & 1,26 & 1,26 & 1,26 & 1,26 & 1,15 & 1,15 & 1,15 & 1,15 & 1,04 & 1,04 & 1,04 & 1,04 \\
\hline Metionina + cistina total $(\%)$ & 0,89 & 0,89 & 0,89 & 0,89 & 0,81 & 0,81 & 0,81 & 0,81 & 0,73 & 0,73 & 0,73 & 0,73 \\
\hline
\end{tabular}

${ }^{1}$ A porção variável foi constituída da enzima fitase e inerte a fim de se obterem os níveis de 0, 500 e 1.000 FTU/kg de ração.

${ }^{2}$ Considerou-se na ração A a disponibilidade de $34 \%$ do fósforo total do milho e do farelo de soja, de acordo com a tabela de composição de alimentos (Rostagno et al., 2000) e, para as outras rações, B, C e D, as disponibilidades de 56,78 e $100 \%$ do fósforo total.

3 Nutrientes por quilograma de ração:

Fase de 1 a 21 dias de idade: vit. A, 10.020 UI; vit. D3, 2.010 UI; vit. E, 15 mg; vit. K3, 2,50 mg; vit. B1, 1,5 mg; vit. B2, 5,01 mg; vit. B6, 1,5 mg; vit. B12, 12 mcg; ácido fólico, 0,6 mg; biotina $0,05 \mathrm{mg}$; niacina, $35 \mathrm{mg}$; pantotenato de cálcio, 11,22 mg; cobre, $6 \mathrm{mg}$; cobalto, $0,10 \mathrm{mg}$; iodo, $1,02 \mathrm{mg}$; ferro, $50 \mathrm{mg}$; manganês, $65 \mathrm{mg}$; zinco, $45 \mathrm{mg}$; selênio, $0,21 \mathrm{mg}$; cloreto de colina (50\%), $700 \mathrm{mg}$; coccidicida, $80 \mathrm{mg}$; promotor de crescimento (bacitracina de zinco), $80 \mathrm{mg}$; antioxidante, $12 \mathrm{mg}$; veículo, $52,8 \%$.

Fase de 22 a 35 dias de idade: vit. A, 8.010 UI; vit.D, 1.800 UI; vit. E, 12 mg; vit. $\mathrm{K}_{3}, 2 \mathrm{mg}$; vit. $\mathrm{B}_{1}, 1 \mathrm{mg}$; vit. $\mathrm{B}_{2}, 4,02 \mathrm{mg}$; vit. B $, 1,02 \mathrm{mg}$; vit. $\mathrm{B}_{12}$, 10,02 mcg; ácido fólico, 0,402 mg; biotina, 0,042 mg; niacina, 28,02 mg; pantotenato de cálcio, 11,22 mg; cobre, $6 \mathrm{mg}$; cobalto, $0,102 \mathrm{mg}$; iodo, 1,02 mg; ferro, $50 \mathrm{mg}$; manganês, $65 \mathrm{mg}$; zinco, $45 \mathrm{mg}$; selênio, 0,21 mg; cloreto de colina (50\%), $500 \mathrm{mg}$; coccidicida, $60 \mathrm{mg}$; promotor de crescimento (bacitracina de zinco), $60 \mathrm{mg}$; antioxidante, $12 \mathrm{mg}$; veículo, $57,8 \%$.

Fase de 36 a 42 dias de idade: vit. A, 5010 UI; vit. $\mathrm{D}_{3}, 1.005$ UI; vit. E, 7 mg; vit. $\mathrm{K}_{3}, 1,2 \mathrm{mg}$; vit. $\mathrm{B}_{1}, 0,3 \mathrm{mg}$; vit. $\mathrm{B}_{2}, 2,4$ mg; vit. $\mathrm{B}_{6}, 0,6 \mathrm{mg}$; vit. B 12,6 mcg; ácido fólico,

0,201 mg; biotina, 0,021 mg; niacina, $17 \mathrm{mg}$; pantotenato de cálcio, $6 \mathrm{mg}$; cobre, $6 \mathrm{mg}$; cobalto, 0,081 mg; iodo, 0,81 mg; ferro, $50 \mathrm{mg}$; manganês, $52 \mathrm{mg}$; zinco, $36 \mathrm{mg}$; selênio, $0,21 \mathrm{mg}$; cloreto de colina $(50 \%), 300 \mathrm{mg}$; antioxidante, $6 \mathrm{mg}$; veículo $(51 \%)$. 
As análises estatísticas foram realizadas utilizando-se o programa SAEG (Euclydes, 1997) e, em caso de significância, as médias foram comparadas pelo teste Tukey a $5 \%$ de probabilidade.

\section{Resultados e Discussão}

$\mathrm{Na}$ fase de 1 a 7 dias de idade (Tabela 4), os níveis de fósforo disponível influenciaram o consumo de ração, o ganho de peso e a conversão alimentar, de forma que a redução a partir do nível de $0,37 \%$ prejudicou o desempenho das aves. Os resultados obtidos para essa fase evidenciam que o menor nível de Pd reduziu o consumo de ração em $13 \%$ em comparação à ração controle, assim como observado por Sebastian et al. (1996), que, utilizando fitase em dietas com baixo nível de fósforo total $(30 \%$ abaixo da recomendação do NRC, 1994), verificaram que o menor nível de Pd reduziu em 14\% o consumo de ração, enquanto, com a adição de fitase, não foram observadas diferenças nessa fase. Nas fases de 0 a 14 e de 0 a 21 dias de idade, a utilização de fitase proporcionou aumento no índice avaliado.

O efeito dos níveis de Pd foi maior sobre a conversão alimentar (Tabela 4), cujo pior resultado foi observado no menor nível de $\mathrm{Pd}$, o que reflete o efeito negativo dos baixos níveis de Pd sobre o consumo de ração e o ganho de peso das aves. Segundo o desdobramento das interações significativas para consumo de ração e ganho de peso $(\mathrm{P}<0,05)$ na fase de 1 a 21 dias de idade (Tabela 4), o ganho de peso foi afetado pela redução de mais de $36 \%$ nos níveis de $\mathrm{Pd}$, pois o menor valor foi obtido com a redução de $54 \%$ e, nesses dois níveis, a inclusão de fitase (500 ou $1.000 \mathrm{ftu} / \mathrm{kg}$ de ração) melhorou o ganho de peso.

Parmer et al. (1987) também verificaram que a redução nos níveis de fósforo disponível das dietas acarretou severa redução no consumo de ração e sugeriram que a deficiência de fósforo pode prejudicar o desempenho das aves, principalmente pela diminuição no consumo de ração, mas também reduz a síntese e a liberação de hormônio de crescimento e de hormônios da tireoide, principalmente T3 (triiodotironina).

O efeito da fitase sobre o consumo de ração em dietas com baixos níveis de Pd foi demonstrado por Lan et al. (2002), Viveros et al. (2002) e Yu et al. (2004), entretanto, esses autores comentaram sobre a importância de se avaliar a fase de criação para determinar o melhor nível de redução de fósforo disponível para essa variável.

$\mathrm{Na}$ fase de 22 a 35 dias de idade (Tabela 5), houve interação significativa entre os níveis de fósforo disponível e os de fitase e, pelo desdobramento, evidenciou-se que o

Tabela 4 - Desempenho de frangos de corte nas fases de 1 a 7 e de 1 a 21 dias de idade e desdobramento das interações entre os níveis de fósforo disponível $(\mathrm{Pd})$ e os de fitase para consumo de ração e ganho de peso na fase de 1 a 21 dias de idade

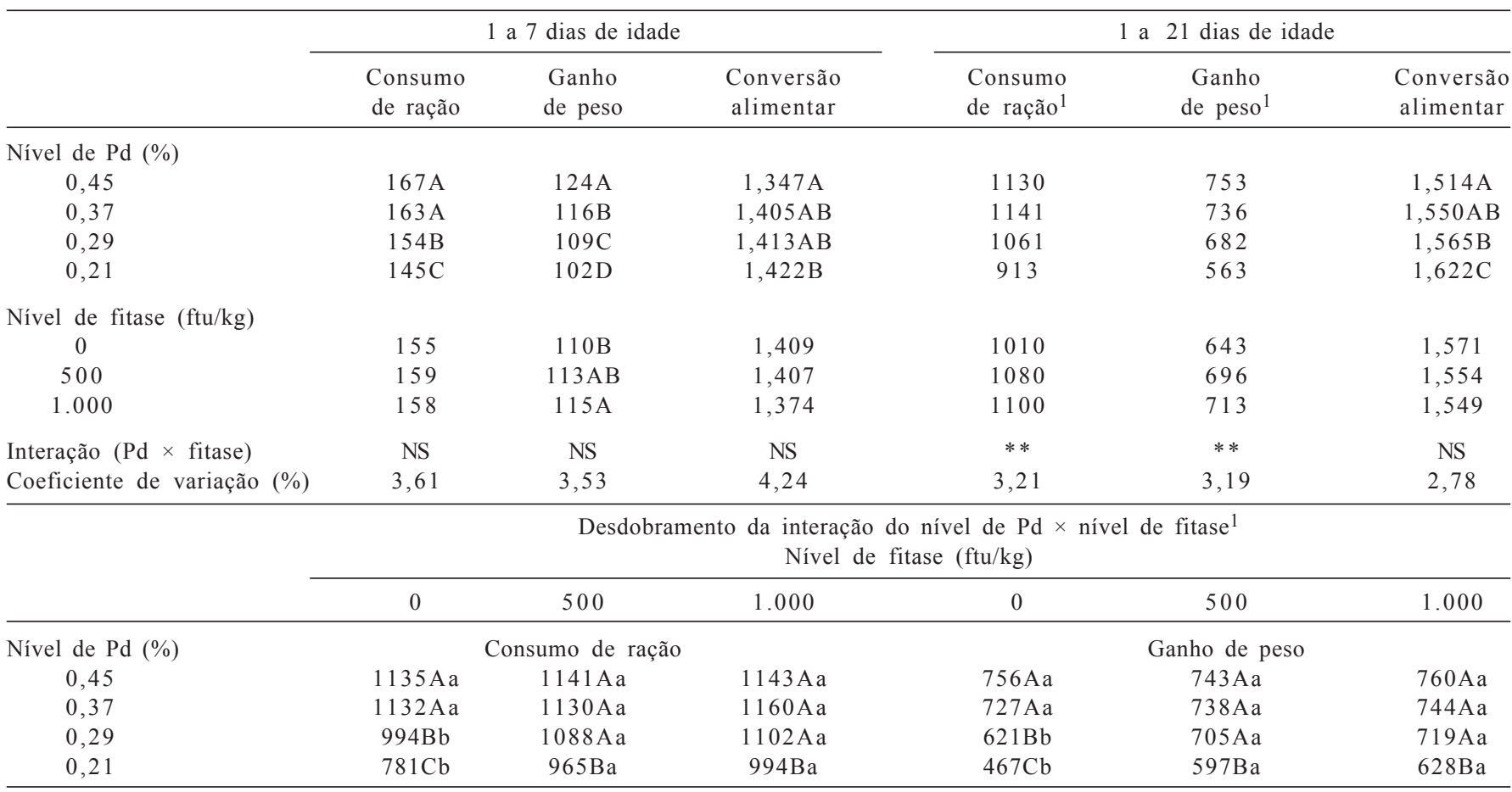

${ }^{1}$ Interação do nível de Pd $(\%) \times$ nível de fitase $(\mathrm{ftu} / \mathrm{kg})(\mathrm{P}<0,01)$.

Médias na coluna seguidas de letras maiúsculas e na linha seguidas de letras minúsculas diferentes são significativas pelo teste de Tukey (P<0,05)

** $\mathrm{P}<0,01 ; * \mathrm{P}<0,05 ; \mathrm{NS}=$ não-significativo. 
menor nível de Pd e a ausência de fitase reduziram o consumo de ração e o ganho de peso. A pior conversão alimentar foi observada também com o fornecimento da dieta sem inclusão de fitase e com o menor nível de Pd, o que comprova a eficiência dessa enzima em melhorar a conversão alimentar no nível $0,17 \%$ Pd.

$\mathrm{Na}$ fase de 36 a 42 dias de idade (Tabela 6), ocorreu interação significativa apenas para consumo de ração $(\mathrm{P}<0,05)$, que, no menor nível de fósforo disponível, foi inferior ao obtido sem adição de fitase na ração. Nos demais níveis de fósforo diponível, não foram encontradas diferenças entre os níveis de fitase avaliados. O menor ganho de peso foi observado quando os níveis de Pd das diferentes fases de criação foram reduzidos em média $58 \%$. Para o efeito isolado dos níveis de fitase nessas fases de criação, a ausência de fitase ( $0 \mathrm{ftu} / \mathrm{kg}$ de ração) promoveu o pior ganho de peso.

Para o período total de criação (1 a 42 dias de idade), interação significativa $(\mathrm{P}<0,01)$ entre níveis de $\mathrm{Pd}$ e os de fitase para todas as variáveis analisadas, exceto a conversão alimentar (Tabela 7). No desdobramento da interação para o consumo de ração nessa fase, os maiores valores para consumo de ração, independentemente dos níveis de fitase, foram observados com a redução média de 19,39 e $58 \%$ nos níveis recomendados por Rostagno et al. (2000), de 0,$45 ; 0,41$ e $0,37 \%$, e com a redução de $19 \%$, para as fases inicial, de crescimento e final. Entretanto, quando os níveis de Pd foram reduzidos em 39 e $58 \%$, constatou-se redução no consumo de ração das aves que receberam ração sem fitase (0 ftu/kg de ração), enquanto, entre aquelas que receberam 500 e $1.000 \mathrm{ftu} / \mathrm{kg}$ de ração, o nível de Pd reduzido em 58\% proporcionou o menor consumo. Para ganho de peso, observou-se a mesma tendência constatada para consumo de ração.

Yan et al. (2004) também não verificaram diferenças significativas no consumo de ração quando reduziram o nível de Pd da dieta controle de $0,35 \%$ para 0,15 e $0,10 \%$ de $\mathrm{Pd}$ (com ou sem a adição de fitase) para frangos de corte na fase de 42 a 63 dias de idade.

$\mathrm{O}$ fato de as aves que receberam dieta com níveis de Pd reduzidos em $39 \%$ apresentarem ganho de peso semelhante ao daquelas alimentadas com a ração controle talvez esteja relacionado à maior atividade enzimática do sistema digestivo das aves mais velhas, fazendo com que o fósforo fítico se tornasse mais disponível, em virtude da baixa exigência de fósforo das aves para os parâmetros de desempenho na fase final de criação. Yan et al. (2004) realizaram experimentos com diversos níveis de Pd para frangos de corte na fase final de criação ( 42 a 63 dias de idade) e não notaram diferenças significativas nos parâmetros de

Tabela 5 - Desempenho de frangos de corte na fase de 22 a 35 dias de idade e desdobramento das interações entre nível de fósforo disponível e níveis de fitase para características de desempenho nessa fase

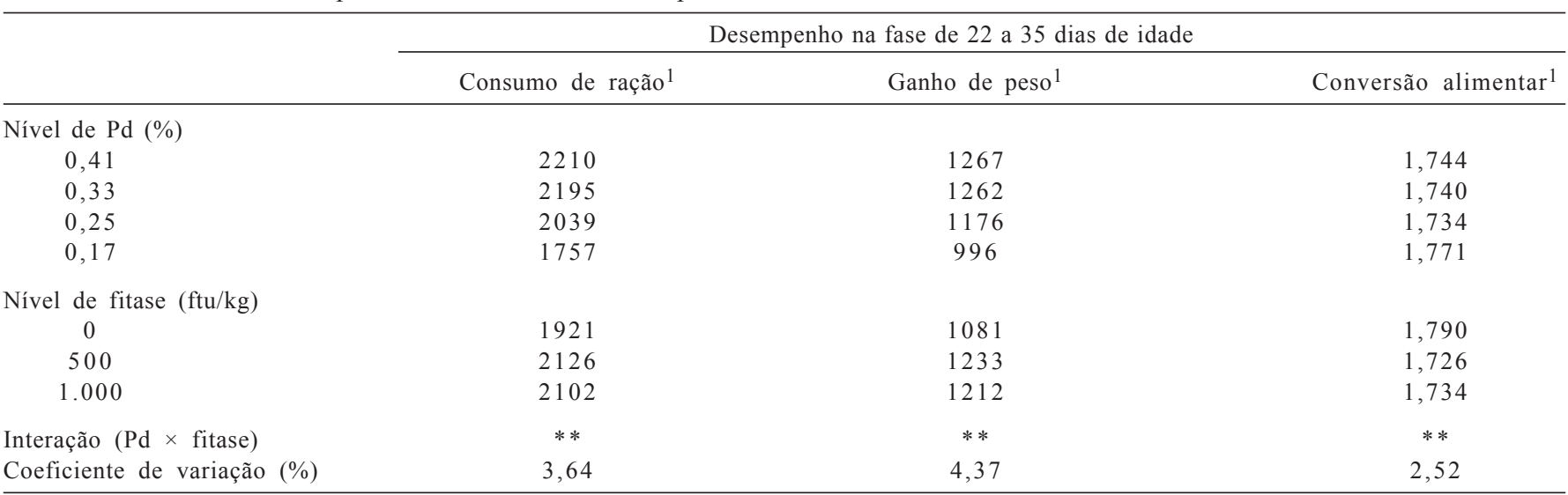

Desdobramento da interação do nível de Pd $\times$ nível de fitase ${ }^{1}$

Nível de fitase $(\mathrm{ftu} / \mathrm{kg})$

\begin{tabular}{|c|c|c|c|c|c|c|c|c|c|}
\hline & \\
\hline & 0 & 500 & 1000 & 0 & 500 & 1.000 & 0 & 500 & 1.000 \\
\hline Nível de Pd (\%) & \multicolumn{3}{|c|}{ Consumo de ração } & \multicolumn{3}{|c|}{ Ganho de peso } & \multicolumn{3}{|c|}{ Conversão alimentar } \\
\hline 0,41 & $2250 \mathrm{Aa}$ & $2198 \mathrm{Aa}$ & $2183 \mathrm{Aa}$ & $1304 \mathrm{Aa}$ & $1263 \mathrm{Aa}$ & $1235 \mathrm{Aa}$ & $1,726 \mathrm{Aa}$ & $1,743 \mathrm{Aa}$ & $1,76 \mathrm{Aa}$ \\
\hline 0,33 & $2153 \mathrm{Aa}$ & $2247 \mathrm{Aa}$ & $2185 \mathrm{Aa}$ & $1222 \mathrm{Aa}$ & $1301 \mathrm{Aa}$ & $1263 \mathrm{Aab}$ & $1,764 \mathrm{Aa}$ & $1,727 \mathrm{Aa}$ & $1,73 \mathrm{Aa}$ \\
\hline 0,25 & $1884 \mathrm{Bb}$ & $2147 \mathrm{Aa}$ & 2086Aab & $1070 \mathrm{Bb}$ & $1263 \mathrm{Aa}$ & 1196Aab & $1,760 \mathrm{Aa}$ & $1,700 \mathrm{Aa}$ & $1,74 \mathrm{Aa}$ \\
\hline 0,17 & $1398 \mathrm{Cb}$ & $1915 \mathrm{Ba}$ & $1957 \mathrm{Ba}$ & $726 \mathrm{Cb}$ & $1106 \mathrm{Ba}$ & $1155 \mathrm{Ba}$ & $1,929 \mathrm{Bb}$ & $1,731 \mathrm{Aa}$ & $1,69 \mathrm{Aa}$ \\
\hline
\end{tabular}

${ }^{1}$ Interação do nível de $\mathrm{Pd}(\%) \times$ nível de fitase $(\mathrm{ftu} / \mathrm{kg})(\mathrm{P}<0,01)$.

Médias na coluna seguidas de letras maiúsculas e na linha seguidas de letras minúsculas diferentes são significativas pelo teste de Tukey $(\mathrm{P}<0,05)$

** $\mathrm{P}<0,01 ; * \mathrm{P}<0,05 ; \mathrm{NS}=$ não-significativo. 
Tabela 6 - Desempenho de frangos de corte nas fases de 36 a 42 dias de idade e desdobramento das interações entre nível de fósforo disponível (Pd) e níveis de fitase para consumo de ração nessa fase

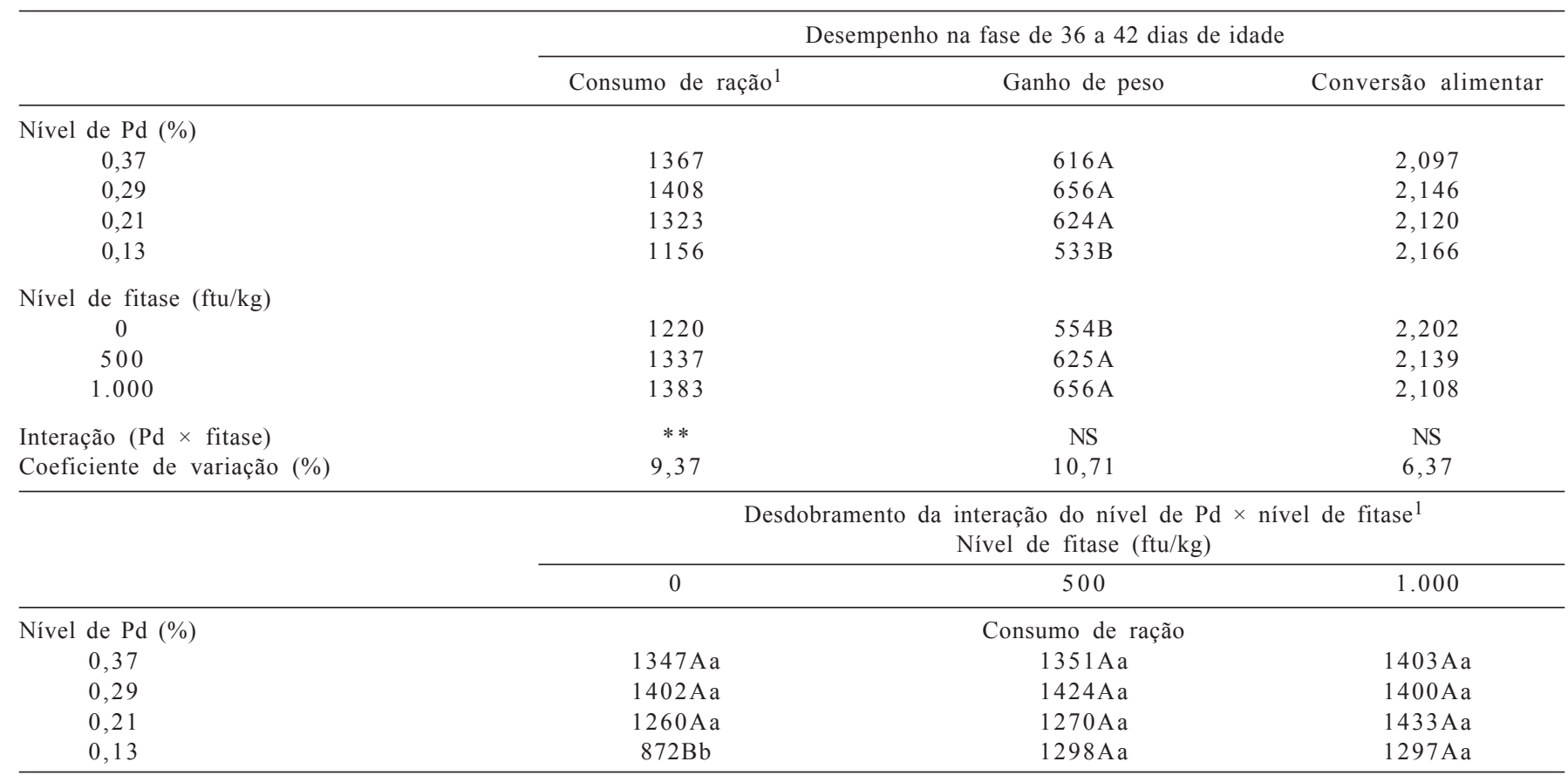

${ }^{1}$ Interação do nível de Pd $(\%) \times$ Nível de fitase $(\mathrm{ftu} / \mathrm{kg})(\mathrm{P}<0,01)$.

Médias na coluna seguidas de letras maiúsculas e na linha seguidas de letras minúsculas diferentes são significativas pelo teste de Tukey $(\mathrm{P}<0,05)$.

** $\mathrm{P}<0,01 ; * \mathrm{P}<0,05 ; \mathrm{NS}=$ não-significativo.

desempenho. Essa redução no consumo de ração, observada também por Biehl et al. (1995), Sebastian et al. (1996), Viveros et al. (2002), Applegate et al. (2003), Yan et al. (2004) e Yu et al. (2004), piora o ganho de peso e esse efeito depende da idade e do percentual de redução do nível de Pd da dieta.

O pior resultado de conversão alimentar (Tabela 7) foi determinado pelo menor nível de Pd e reflete o efeito dos níveis de Pd sobre o consumo de ração e o ganho de peso das aves. Para o efeito isolado da adição de fitase, o pior resultado foi obtido com a ração sem fitase $(0 \mathrm{ftu} / \mathrm{kg}$ de ração). Ocorreram interações significativas $(\mathrm{P}<0,05)$ para a viabilidade criatória e para o índice de eficiência de produção (Tabela 8). O menor nível de Pd, na ausência de fitase ou com adição de $500 \mathrm{ftu} / \mathrm{kg}$ de ração, promoveu redução na viabilidade criatória. Entretanto, nesse mesmo nível de Pd, a adição de 500 ou de $1.000 \mathrm{ftu}$ de fitase na ração melhorou a viabilidade criatória em comparação à ausência de fitase.

O menor nível de Pd sem a adição de fitase proporcionou o pior índice de eficiência produtiva, uma vez que essas aves apresentaram os piores índices de desempenho. Entretanto, no menor nível de Pd, a adição de fitase determinou melhora, de modo que o melhor índice foi obtido com a adição de $1.000 \mathrm{ftu} / \mathrm{kg}$ de ração.

As características da cama dos frangos foram influenciadas $(\mathrm{P}<0,05)$ pelas interações entre o coeficiente de resíduo e a porcentagem de fósforo total (Tabela 9) e provavelmente estão relacionadas ao consumo de ração e ao ganho de peso (Tabela 7). Dessa forma, com menor produção de peso vivo por unidade experimental e produção de cama similar entre os níveis de fósforo disponível e fitase, o coeficiente de resíduo tornou-se maior. O ideal é que o coeficiente de resíduo seja o menor possível para diminuir o impacto ambiental da atividade.

O menor ganho de peso das aves proporcionou maior coeficiente de resíduo nas dietas com redução média de $58 \%$ nos níveis de Pd sem a adição de fitase. Nesse mesmo nível de $\mathrm{Pd}$, a adição de $500 \mathrm{ftu}$ de fitase/kg de ração reduziu o coeficiente de resíduo, entretanto o menor valor foi observado com a adição de $1.000 \mathrm{ftu} / \mathrm{kg}$ de ração, que promoveu maior coeficiente de resíduo nos níveis de Pd reduzidos em todas as fases.

Os níveis de fósforo disponível reduzidos em 39 e 58\% determinaram os menores teores de fósforo total, na cama, em decorrência das reduções nos níveis e na consequente diminuição do consumo de ração. Segundo Mouchrek (1996), o consumo de ração é um dos principais fatores que afetam a composição da cama. A redução média de fósforo total da cama foi de $39 \%$, valor próximo ao relatado por Applegate et al. (2003), que, ao reduzirem o teor de fósforo da dieta por meio da suplementação com fitase nas diversas fases de criação, verificaram aos 49 dias de idade a redução 
média de 33\% no Pt da cama em comparação ao observado com o fornecimento da dieta controle.

Isoladamente, apenas os níveis de fósforo influenciaram o teor de proteína bruta da cama $(\mathrm{P}<0,05)$, que atingiu os maiores valores nos maiores níveis de $\mathrm{Pd}$ na ração, provavelmente em decorrência do maior consumo de ração. Os níveis de Pd afetaram os teores de cinzas, $\mathrm{P}, \mathrm{Mn}$ e Zn nas tíbias (Tabela 10), que foram menores nos níveis de Pd reduzidos em 39 e 58\%. A adição de fitase ocasionou diferenças significativas nos teores de cinzas, fósforo e

Tabela 7 - Desempenho de frangos de corte na fase de 1 a 42 dias de idade e desdobramento das interações entre níveis de fósforo disponível e níveis de fitase para consumo de ração e ganho de peso nessa fase

\begin{tabular}{|c|c|c|c|c|c|}
\hline \multicolumn{3}{|c|}{ Nível de Pd (\%) } & \multicolumn{3}{|c|}{ Desempenho na fase de 1 a 42 dias de idade } \\
\hline 1 a 21 dias & 22 a 35 dias & 36 a 42 dias & Consumo de ração ${ }^{1}$ & Ganho de peso ${ }^{1}$ & Conversão alimentar \\
\hline 0,45 & 0,41 & 0,37 & 4717 & 2672 & $1,765 \mathrm{~A}$ \\
\hline 0,37 & 0,33 & 0,29 & 4744 & 2654 & $1,787 \mathrm{~A}$ \\
\hline 0,29 & 0,25 & 0,21 & 4423 & 2479 & $1,785 \mathrm{~A}$ \\
\hline 0,21 & 0,17 & 0,13 & 3826 & 2091 & $1,829 \mathrm{~B}$ \\
\hline \multicolumn{6}{|c|}{ Nível de fitase (ftu/kg) } \\
\hline 0 & & & 4152 & 2283 & $1,823 \mathrm{~B}$ \\
\hline 500 & & & 4545 & 2554 & $1,779 \mathrm{~A}$ \\
\hline 1.000 & & & 4586 & 2584 & $1,776 \mathrm{~A}$ \\
\hline \multicolumn{3}{|c|}{ Interação $(\mathrm{Pd} \times$ fitase $)$} & $* *$ & $* *$ & NS \\
\hline \multicolumn{3}{|c|}{ Coeficiente de variação (\%) } & 3,86 & 3,79 & 2,37 \\
\hline
\end{tabular}

Desdobramento da interação do nível de Pd $\times$ nível de fitase Nível de fitase $(\mathrm{ftu} / \mathrm{kg})$

\begin{tabular}{|c|c|c|c|c|c|c|c|c|}
\hline \multicolumn{3}{|c|}{ Nível de Pd (\%) } & 0 & 500 & 1.000 & 0 & 500 & 1.000 \\
\hline 1 a 21 dias & 22 a 35 dias & 36 a 42 dias & \multicolumn{3}{|c|}{ Consumo de ração } & \multicolumn{3}{|c|}{ Ganho de peso } \\
\hline 0,45 & 0,41 & 0,37 & $4732 \mathrm{Aa}$ & $4690 \mathrm{Aa}$ & $4730 \mathrm{Aa}$ & $2675 \mathrm{Aa}$ & $2670 \mathrm{Aa}$ & $2671 \mathrm{Aa}$ \\
\hline 0,37 & 0,33 & 0,29 & $4687 \mathrm{Aa}$ & $4801 \mathrm{Aa}$ & $4745 \mathrm{Aa}$ & $2591 \mathrm{Aa}$ & $2683 \mathrm{Aa}$ & $2689 \mathrm{Aa}$ \\
\hline 0,29 & 0,25 & 0,21 & $4137 \mathrm{Bb}$ & $4511 \mathrm{Aa}$ & $4622 \mathrm{Aa}$ & $2276 \mathrm{Bb}$ & $2558 \mathrm{Aa}$ & $2603 \mathrm{Aa}$ \\
\hline 0,21 & 0,17 & 0,13 & $3052 \mathrm{Cb}$ & $4178 \mathrm{Ba}$ & $4248 \mathrm{Ba}$ & $1590 \mathrm{Cb}$ & $2305 \mathrm{Ba}$ & $2376 \mathrm{Ba}$ \\
\hline
\end{tabular}

${ }^{1}$ Interação do nível de $\mathrm{Pd}(\%) \times$ nível de fitase $(\mathrm{ftu} / \mathrm{kg})(\mathrm{P}<0,01)$.

Médias na coluna seguidas de letras maiúsculas e na linha seguidas de letras minúsculas diferentes são significativas pelo teste Tukey (P<0,05).

** $\mathrm{P}<0,01 ; * \mathrm{P}<0,05 ; \mathrm{NS}=$ não-significativo.

Tabela 8 - Viabilidade criatória e índice de eficiência produtiva de frangos de corte na fase de 1 a 42 dias de idade e desdobramento das interações entre nível de fósforo disponível e níveis de fitase

\begin{tabular}{|c|c|c|c|c|}
\hline \multicolumn{3}{|c|}{ Nível de Pd (\%) } & \multirow[t]{2}{*}{ Viabilidade criatória $(\%)^{1}$} & \multirow[t]{2}{*}{ Índice de eficiência produtiva } \\
\hline 1 a 21 dias & 22 a 35 dias & 36 a 42 dias & & \\
\hline 0,45 & 0,41 & 0,37 & 98 & 352 \\
\hline 0,37 & 0,33 & 0,29 & 97 & 343 \\
\hline 0,29 & 0,25 & 0,21 & 98 & 324 \\
\hline 0,21 & 0,17 & 0,13 & 88 & 240 \\
\hline \multicolumn{5}{|c|}{ Nível de fitase (ftu/kg) } \\
\hline 0 & & & 92 & 281 \\
\hline 500 & & & 95 & 326 \\
\hline 1.000 & & & 99 & 340 \\
\hline \multicolumn{3}{|c|}{ Interação $(\mathrm{Pd} \times$ fitase $)$} & $* *$ & $* *$ \\
\hline \multicolumn{3}{|c|}{ Coeficiente de variação $(\%)$} & 4,53 & 6,11 \\
\hline
\end{tabular}

Desdobramento da interação do nível de Pd $\times$ nível de fitase ${ }^{1}$ Nível de fitase $(\mathrm{ftu} / \mathrm{kg})$

\begin{tabular}{|c|c|c|c|c|c|c|c|c|}
\hline \multicolumn{3}{|c|}{ Nível de Pd (\%) } & 0 & 500 & 1000 & 0 & 500 & 1.000 \\
\hline 1 a 21 dias & 22 a 35 dias & 36 a 42 dias & \multicolumn{3}{|c|}{ Viabilidade criatória } & \multicolumn{3}{|c|}{ Índice de eficiência produtiva } \\
\hline 0,45 & 0,41 & 0,37 & $98 \mathrm{Aa}$ & $98 \mathrm{Aa}$ & $100 \mathrm{Aa}$ & $335 \mathrm{Aa}$ & $357 \mathrm{Aa}$ & $358 \mathrm{Aa}$ \\
\hline 0,37 & 0,33 & 0,29 & $96 \mathrm{Aa}$ & $98 \mathrm{Aa}$ & $98 \mathrm{Aa}$ & $326 \mathrm{Aa}$ & $348 \mathrm{Aa}$ & $355 \mathrm{Aa}$ \\
\hline 0,29 & 0,25 & 0,21 & $99 \mathrm{Aa}$ & $97 \mathrm{Aa}$ & $98 \mathrm{Aa}$ & $293 \mathrm{Bb}$ & $336 \mathrm{Aa}$ & $341 \mathrm{Aa}$ \\
\hline 0,21 & 0,17 & 0,13 & $78 \mathrm{Bc}$ & $88 \mathrm{Bb}$ & $99 \mathrm{Aa}$ & $147 \mathrm{Cc}$ & $261 \mathrm{Bb}$ & $313 \mathrm{Ba}$ \\
\hline
\end{tabular}

${ }^{1}$ Interação do nível de Pd (\%) × nível de fitase $(\mathrm{ftu} / \mathrm{kg})(\mathrm{P}<0,01)$.

Médias na coluna seguidas de letras maiúsculas e na linha seguidas de letras minúsculas diferentes são significativas pelo teste de Tukey (P<0,05).

** $\mathrm{P}<0,01 ; * \mathrm{P}<0,05 ; \mathrm{NS}=$ não-significativo. 
Tabela 9 - Coeficiente de resíduo, concentrações de proteína bruta e fósforo total das camas de frango e desdobramento das interações entre nível de fósforo disponível (Pd) e níveis de fitase para coeficiente de resíduo e fósforo total nessa fase

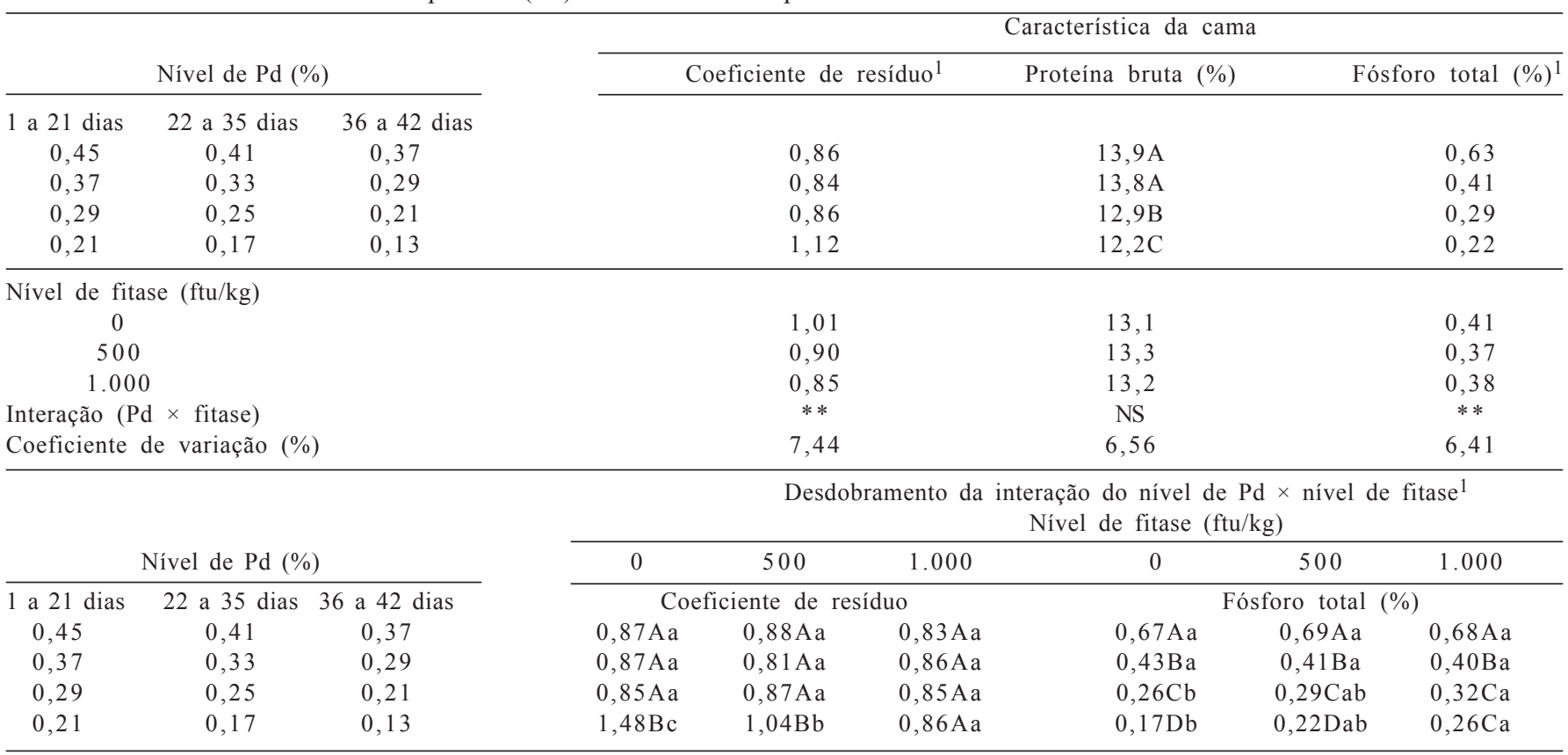

${ }^{1}$ Interação do nível de Pd (\%) $\times$ nível de fitase $(\mathrm{ftu} / \mathrm{kg})(\mathrm{P}<0,01)$.

Médias na coluna seguidas de letras maiúsculas e na linha seguidas de letras minúsculas diferentes são significativas pelo teste de Tukey $(\mathrm{P}<0,05)$.

** $\mathrm{P}<0,01 ; * \mathrm{P}<0,05 ; \mathrm{NS}=$ não-significativo.

Tabela 10 - Teores de cinzas e concentrações de fósforo total, manganês, cobre e zinco nas tíbias e no fígado de frangos de corte aos 42 dias de idade

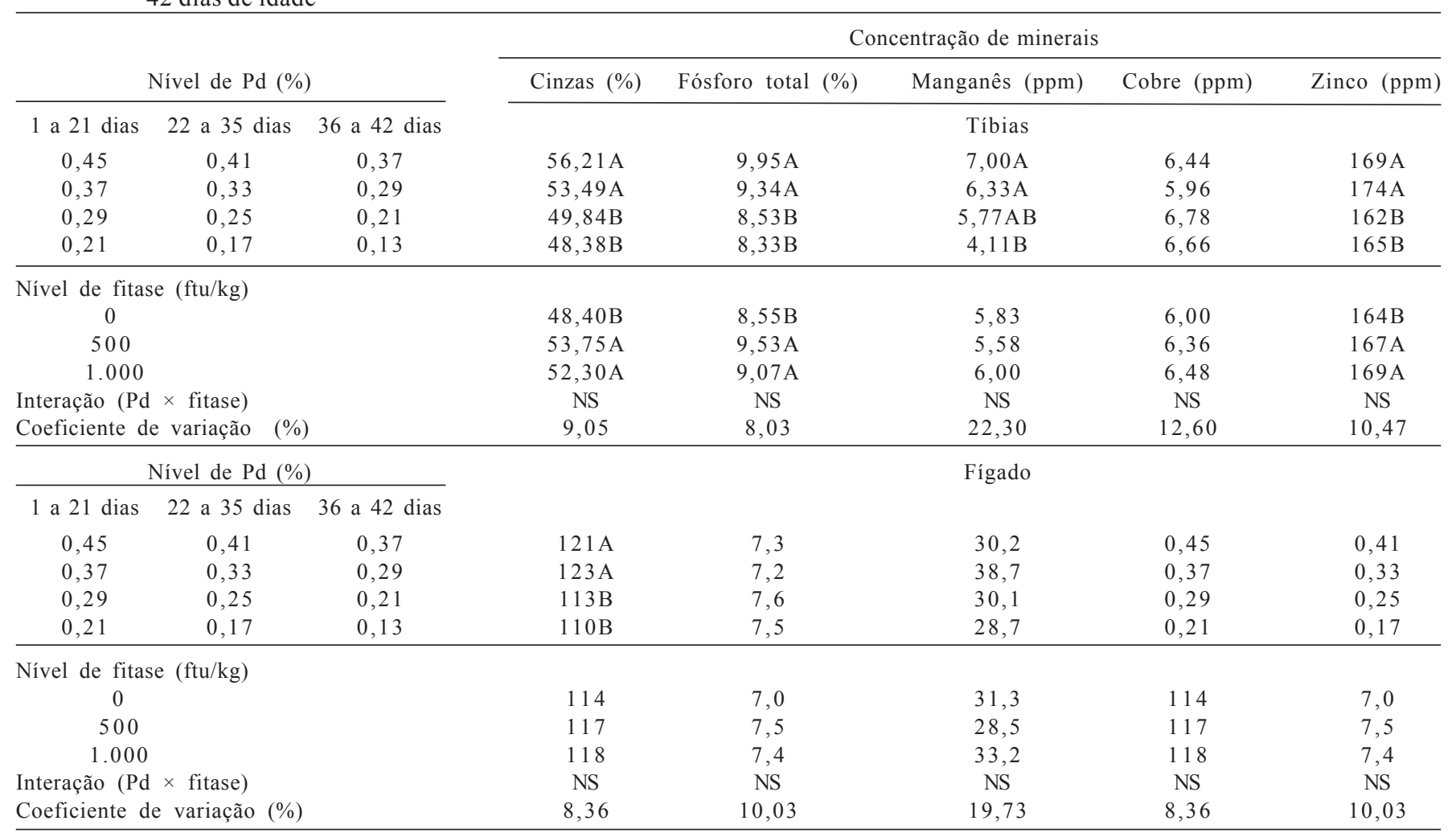

Médias na coluna seguidas de letras maiúsculas e na linha seguidas de letras minúsculas diferentes são significativas pelo teste de Tukey (P<0,05).

** $\mathrm{P}<0,01 ; * \mathrm{P}<0,05 ; \mathrm{NS}=$ não-significativo. 
zinco nas tíbias, uma vez que a não-utilização de fitase (0 ftu/kg de ração) resultou em valores mais baixos.

Os menores teores de cinzas, fósforo e zinco para as aves alimentadas com as rações com níveis reduzidos de Pd (Tabela 10) podem ser atribuídos à redução na ingestão de fósforo com a diminuição dos níveis de $\mathrm{Pd}$ das rações e do consumo de ração, o que diminuiu a ingestão dos microminerais. Os resultados obtidos para os teores de cinzas e de $\mathrm{P}$ nas tíbias confirmam os dados apresentados por Viveros et al. (2002), Lan et al. (2002) e Banks et al. (2004), que também verificaram redução nos teores de cinzas e de $\mathrm{P}$ nas tíbias com a redução de $\mathrm{Pd}$ da dieta e, ao utilizarem a enzima fitase, e elevação nos teores de cinzas e fósforo nas tíbias. Entretanto, os valores obtidos para $\mathrm{Mn}$ e Zn nas tíbias diferem dos obtidos por Lan et al. (2002), que, ao reduzirem os níveis de $\mathrm{Pd}$ de 0,46 para $0,24 \%$ e de 0,35 para $0,23 \%$, respectivamente, na ração de frangos nas fases de 1 a 21 dias e de 22 a 42 dias de idade, verificaram que o nível de manganês aumentou no menor nível de $\mathrm{Pd}$, enquanto os de zinco não apresentaram diferenças.
O efeito positivo da fitase sobre a deposição de minerais na tíbia pode ser atribuído à disponibilização do $\mathrm{P}$ e $\mathrm{Zn}$ complexado ao ácido fítico, confirmando os valores descritos por Biehl et al. (1995). Independentemente da adição de fitase, os níveis de Pd influenciaram o teor de zinco no fígado (Tabela 10), de forma que, nos níveis de $\mathrm{Pd}$ reduzidos em 38 e 58\%, houve redução dos teores de $\mathrm{Zn}$ no fígado das aves. Essa diferença está relacionada ao consumo de ração, que foi afetado pelos níveis de $\mathrm{Pd}$, entretanto não foram observadas diferenças na deposição dos outros microminerais.

Conte et al. (2002), estudando diferentes níveis de Pd em dietas contendo farelo de arroz, com e sem a adição de fitase, não notaram diferenças nos teores de $\mathrm{Zn}, \mathrm{Mn}$ e $\mathrm{Cu}$ no fígado de frangos de corte aos 42 dias de idade. Nesta pesquisa, somente a porcentagem de fósforo nas excretas interação foi afetada pela interação $(\mathrm{P}<0,05)$ entre os níveis de $\mathrm{Pd}$ e a adição de fitase (Tabela 11). A concentração dos demais microminerais não apresentou diferenças significativas. Independentemente dos níveis de fitase, a

Tabela 11 - Concentrações de minerais nas excretas dos frangos de corte aos 42 dias de idade

\begin{tabular}{|c|c|c|c|c|}
\hline Nível de Pd (\%) & Fósforo total $(\%)^{1}$ & Manganês (ppm) & Cobre (ppm) & Zinco (ppm) \\
\hline $\begin{array}{r}0,41 \\
0,33 \\
0,25 \\
0,17\end{array}$ & $\begin{array}{l}1,26 \\
0,96 \\
0,72 \\
0,58\end{array}$ & $\begin{array}{l}297 \\
290 \\
290 \\
279\end{array}$ & $\begin{array}{l}270 \\
258 \\
262 \\
256\end{array}$ & $\begin{array}{l}319 \\
292 \\
314 \\
319\end{array}$ \\
\hline $\begin{array}{l}\text { Nível de fitase }(\mathrm{ftu} / \mathrm{kg}) \\
0 \\
500 \\
1.000 \\
\text { Interação }(\mathrm{Pd} \times \text { fitase }) \\
\text { Coeficiente de variação }(\%)\end{array}$ & $\begin{array}{c}0,75 \\
0,92 \\
0,98 \\
* * \\
5,67\end{array}$ & $\begin{array}{c}281 \\
295 \\
290 \\
\mathrm{NS} \\
6,1\end{array}$ & $\begin{array}{c}248 \\
257 \\
250 \\
\mathrm{NS} \\
6,66\end{array}$ & $\begin{array}{c}304 \\
315 \\
314 \\
\mathrm{NS} \\
8,62\end{array}$ \\
\hline & \multicolumn{4}{|c|}{$\begin{array}{l}\text { Desdobramento da interação do nível de Pd } \times \text { nível de fitase }{ }^{1} \\
\text { Nível de fitase }(\mathrm{ftu} / \mathrm{kg})\end{array}$} \\
\hline & 0 & \multicolumn{2}{|c|}{500} & 1.000 \\
\hline Nível de Pd (\%) & \multicolumn{4}{|c|}{ Concentração de fósforo total } \\
\hline $\begin{array}{l}0,41 \\
0,33 \\
0,25 \\
0,17\end{array}$ & $\begin{array}{c}1,09 \mathrm{Ab} \\
0,75 \mathrm{Bc} \\
0,64 \mathrm{BCb} \\
0,53 \mathrm{Ca}\end{array}$ & $\begin{array}{l}1,3 \\
1,0 \\
0,7 \\
0,5\end{array}$ & & $\begin{array}{l}1,36 \mathrm{Aa} \\
1,14 \mathrm{Ba} \\
0,77 \mathrm{Ca} \\
0,64 \mathrm{Da}\end{array}$ \\
\hline
\end{tabular}

${ }^{1}$ Interação do nível de Pd $(\%) \times$ nível de fitase $(\mathrm{ftu} / \mathrm{kg})(\mathrm{P}<0,01)$.

Médias na coluna seguidas de letras maiúsculas e na linha seguidas de letras minúsculas diferentes são significativas $(P<0,05)$ pelo teste de Tukey. ** $\mathrm{P}<0,01 ; * \mathrm{P}<0,05 ; \mathrm{NS}=$ não-significativo.

redução dos níveis de $\mathrm{Pd}$ das rações ocasionou diminuição média de $40 \%$ na quantidade de fósforo nas excretas em comparação ao maior nível de $\mathrm{Pd}$.

A utilização de $1.000 \mathrm{ftu} / \mathrm{kg}$ de ração elevou o teor de fósforo nas excretas para quase todos os níveis de $\mathrm{Pd}$ das rações em relação à ausência de fitase, com exceção do menor nível $(0,17 \%)$, no qual não foram verificadas diferenças entre os níveis de fitase utilizados. O efeito da fitase em cada nível de Pd evidencia novamente a eficiência dessa enzima sobre a utilização do fósforo complexado ao inositol, confirmando os resultados encontrados por Biehl et al. (1995), Ravidran etal.(1995), Batal et al. (2001) e Banks etal. (2004). 


\section{Conclusões}

A redução média de até $39 \%$ nos níveis de fósforo disponível e a disponibilização de $78 \%$ do fósforo total do milho e do farelo de soja por meio da adição da enzima fitase aumentam a biodisponibilidade do fósforo fítico e não afetam o desempenho das aves. A adição de $500 \mathrm{ftu} / \mathrm{kg}$ de ração é suficiente para garantir o desempenho de frangos de corte quando os níveis de fósforo disponível da ração são reduzidos em média 18 e $36 \%$ em relação ao ideal. A adição de fitase nas rações possibilita reduzir os níveis de Pd das dietas e diminuir a excreção de fósforo, contribuindo para a redução do poder poluente da cama de frango, o que seria uma prática ecologicamente correta.

\section{Agradecimentos}

À FAPESP, pelo auxílio financeiro concedido processo 2001/12967-6.

\section{Literatura Citada}

APPlEGATE, T.J.; ANGEL, R.; CLASSEN, H.L. Effect of dietary calcium, 25-hydroxycholecal-ciferol, or bird strain on small intestinal phytase activity in broiler chickens. Poultry Science, v.82, p.1140-1148, 2003.

ASSOCIATION OF OFFICIAL AGRICULTURAL CHEMISTS AOAC. Official methods of analysis. 15.ed. Arlington: Association of Official Analytical Chemists, 1990. n.1. 1117p.

BANKS, K.M.; THOMPSON, K.L.; JAYNES, P. et al. The effects of copper on the efficacy of phytase, growth, and phosphorus retention in broiler chicks. Poultry Science, v.83, p.1335-1341, 2004.

BATAL, A.B.; PARR, T.M.; BAKER, D.H. Zinc bioavailability in tetrabasic zinc chloride and the dietary zinc requirement of Young chicks fed a soy concentrate diet. Poultry Science, v.80, n.1, p.87-90, 2001.

BELLAVER, C.; GUIDONI, A.L.; ALBINO, L.F.T. et al. Fontes e níveis de fosfatos de rocha sobre o desempenho de frangos de corte. Pesquisa Agropecuária Brasileira, v.22, n.9/10, p.1085-1091, 1987

BIEHL, R.R.; BAKER, D.H.; DeLUCA, H.F. $1 \mu$-Hydroxylated cholecalciferol compounds act additively with microbial phytase to improve phosphorus zinc and manganese utilization in chicks fed soy-based diets. Journal of Nutrition, v.125, p.2407-2416, 1995.

BORGES, F.M.O. Utilização de enzimas em dietas avícolas. Caderno Técnico da Escola de Veterinária da UFMG, n.20, p.5-30, 1997.

CONTE, A.J.; TEIXEIRA, A.S.; FIGUEIREDO, A.V. et al. Efeito da fitase na biodisponibilidade do fósforo do farelo de arroz em frangos de corte. Pesquisa Agropecuária Brasileira, v.37, n. 4, p. 537-552, 2002.
DENBOW, D.M.; RAVINDRAN, V.; KONERGAY, E.T. et al Improving phosphorus availability in soybean meal for broilers by supplemental phytase. Poultry Science, v.74, p.1831-1842, 1995.

EUCLYDES, R.F. Sistema para análises estatísticas. SAEG versão 7.1. Viçosa, MG: Fundação Arthur Bernardes, 1997. 59p.

GOMES, P.C.; GOMES, M.F.M.; LIMA, G.J.M.M. et al. Exigência de fósforo e sua disponibilidade nos fosfatos monoamônio e monocálcio para frangos de corte até 21 dias de idade. Revista da Sociedade Brasileira de Zootecnia, v.22, n.5, p.755-763, 1993.

JUNQUEIRA, O.M.; KNOOP, R.; SAKOMURA, N.K. 1993. Meat and bone meal and dicalcium phosphate as phosphorus sources in broilers diets. Poultry Science, v.72, p.123, 1993 (suppl.1).

LAN, G.Q.; ABDULLAH, N.; JALALUDIN, S. et al. Efficacy of supplementation of a phytase-producing bacterial culture on the performance and nutrient use of broiler chickens fed cornsoybean meal diets. Poultry Science, v.81, p.1522-1532, 2002.

MOUCHREK, E. Manejo de cama - materiais alternativos. In: CURSO MANEJO DE FRANGOS DE CORTE, Campinas, 1996. Anais... Campinas: Fundação APINCO de Ciência e Tecnologia Avícolas, 1996. p.47-67.

NATIONAL RESEARCH COUNCIL - NRC. Nutrient requirement of poultry. 9.ed. Washington, D.C.: National Academy of Sciences, 1994. 156p.

PARMER, T.G.; KIRBY, L.K.; JOHNSON, Z.B. Function, growth hormone, and organ growth in broiler deficien in phosphorus. Poultry Science, v.66, p.1995-2004, 1987.

QIAN, H.; VEIT, H.P.; KONERGAY, E.T. et al. Effects of supplemental phytase and phosphorus on histological and other tibial bone characteristics and performances of broilers fed semipurified diets. Poultry Science, v.75, p.618-626, 1996.

ROSTAGNO, H.S.; ALBINO, L.F.T.; DONZELE, J.L. et al. Tabelas brasileiras para aves e suínos: composição de alimentos e exigências nutricionais. Viçosa, MG: Universidade Federal de Viçosa, 2000. 141p.

RAVINDRAN, V.; BRYDEN, W.L.; KORNEGAY, E.T. Phytates: Occurrence, biavailability and implicatíons in poultry nutrition. Poultry and Avian Biology Reviews, v.6, n.2, p.125-143, 1995.

SEBASTIAN, S.; TOUCHBURN, S.P.; CHAVEZ, E.R. et al. The effects of supplemental microbial phytase on the performance and utilization of dietary calcium, phosphorus, copper and zinc in broiler chickens fed corn-soybean diets. Poultry Science, v.75, p.729-736, 1996.

SILVA, D.J. Análise de alimentos (métodos químicos e biológicos) Viçosa, MG: Universidade Federal de Viçosa, 1990. 165p.

VIVEROS, A.; BRENES, A.; ARIJA, I. et al. Effects of microbial pitase supplementation on mineral utilization and serum enzyme activities in broiler chicks fed different levels of phosphorus. Poultry Science, v.81, p.1172-1183, 2002.

YAN, F.; FRITTS, C.A.; WALDROUP, P.W. Evaluation of modified dietary phosphorus levels with and without phytase supplementation on live performance and excreta phosphorus concentration in broiler diets. 2. modified early phosphorus levels. Journal of Applied Poultry Research, v.13, p.394-400, 2004.

YU, B.; JAN, Y.; CHUNG, T. et al. Exogenous phytase activity in the gastrointestinal tract of broiler chickens. Animal Feed Science and Technology, v.117, p.295-303, 2004. 